This item was submitted to Loughborough's Research Repository by the author.

Items in Figshare are protected by copyright, with all rights reserved, unless otherwise indicated.

\title{
Effect of annular slots on the solid conical antenna
}

PLEASE CITE THE PUBLISHED VERSION

http://dx.doi.org/10.1109/ROPACES.2016.7465419

PUBLISHER

(c) IEEE

VERSION

AM (Accepted Manuscript)

LICENCE

CC BY-NC-ND 4.0

REPOSITORY RECORD

Agunlejika, Oluwafunmilayo, James A. Flint, and R.D. Seager. 2019. "Effect of Annular Slots on the Solid Conical Antenna". figshare. https://hdl.handle.net/2134/23289. 


\title{
Solid Conical Antenna with Annular Slots
}

\author{
O. Agunlejika*, J. A. Flint and R. D. Seager \\ School of Electronic, Electrical and Systems Engineering, Loughborough University, LE11 3TU, United Kingdom \\ *O.Agunlejika@lboro.ac.uk, J.A.Flint@lboro.ac.uk, R.D.Seager@lboro.ac.uk
}

\begin{abstract}
The effects of adding annular slots to solid conical antenna is described in this paper. The slots produced stop-bands with anti-resonant frequencies that are inversely proportional to the depth of the slots. The addition of double slots produced two distinct stop-bands. Prototype antennas were fabricated and measured to verify the simulated results.
\end{abstract}

Keywords - annular slot; antenna measurement; anti-resonant frequency; conical antenna; slotted antenna; stop-band; trap frequency

\section{INTRODUCTION}

For both military and commercial applications, there is an increasing demand for Ultra Wide Band (UWB) antennas with omni-directional coverage [1]. Conical antenna structures possess characteristics such as broad bandwidth and an omnidirectional radiation pattern, which attracted research interest to them[2]-[8]. In this paper, the effects of adding slots to solid conical antenna are presented. Simulated results were obtained using CST Microwave studio and a time domain Transmission Line Modelling numerical method. The effect of radial slot on the radiating frequency of the solid conical antenna was investigated. Both single and double slot applications were investigated. In order to validate the simulated results, prototype antennas were fabricated and measured.

The simulated and measured results of the slotted-cone antennas are presented in the section III. The results are discussed in section IV.

\section{METHOD}

For an operating frequency of $2 \mathrm{GHz}$, the vertical length of plain cone antenna simulated and measured as a benchmark for the slotted-cone was set at $\lambda / 4=37.5 \mathrm{~mm}$; the diameter of the circular base was $75 \mathrm{~mm}$ and the antenna's cone half-angle was $45^{\circ}$. The antenna was modelled to stand on a circular plane ground of radius $150 \mathrm{~mm}$. The prototype antennas were built using solid copper material while the ground planes were constructed from a single sided copper-clad FR4. A hole was drilled to the base of the cone to serve as the connecting point to the 50 ohms SMA connector. The schematic diagram of the simulated cone and the picture of the prototype cone are as shown in Fig. 1. For a general overview of the antennas' behaviour, an Anristsu 37397D VNA analyser calibrated to measure up to $12 \mathrm{GHz}$ frequency was used for the measurement of the reflection coefficient (S11) of the antennas. The analyser was connected to the coaxial feed, which was connected to the ground plane.
Fig. 2 shows that the simulated result for the plain cone was broadband in nature as theoretically expected. However, the bandwidth of the measured result was not as wide as the simulated one.

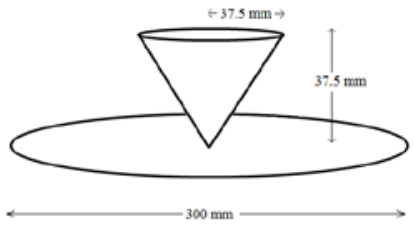

(a)

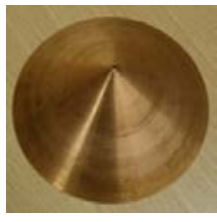

(b)
Fig. 1. (a) The schematic diagram of the simulated plain cone antenna, (b) The picture of the fabricated prototype plain cone antenna.

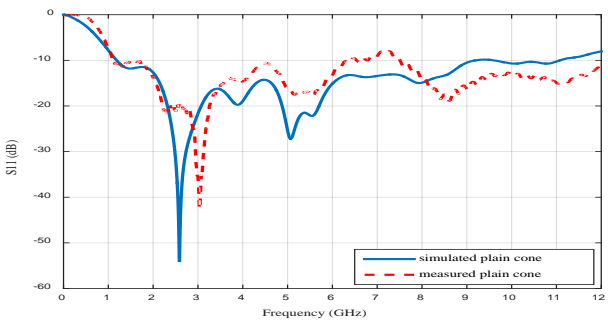

Fig. 2. Comparison of the simulated and measured operating frequencies for the plain cone.

\section{Slotted CONE ANTENNA: Simulation AND MEASURED RESULTS}

The effect of the slot on the operating frequency of the conical antenna was investigated and reported in this section. The result obtained from the simulated plain cone discussed in section II is used as reference for the results of the slotted cones simulated in this section. The measurement set-up for the plain cone was also adopted for the slotted cone measurements to facilitate easy comparison.

In order to evaluate the impact of slot on the performance of the slotted-cone antenna, two simulations were conducted. An annular slot of $7.5 \mathrm{~mm}$ deep was placed on the cone at $18.75 \mathrm{~mm}$ cone-height for the first simulation and $15 \mathrm{~mm}$ deep slot used for the second simulation was positioned at $26.25 \mathrm{~mm}$ cone-height as shown in Fig. 3(a) and 3(b). The slot-width for both simulations was $3 \mathrm{~mm}$. The sample prototype slotted cone antenna fabricated with $15 \mathrm{~mm}$ deep and $3 \mathrm{~mm}$ wide slot positioned at $26.25 \mathrm{~mm}$ cone height is shown in Fig. 3c. The simulated and measured results are presented in Fig. 4. 


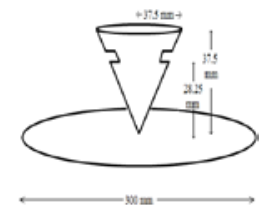

(a)

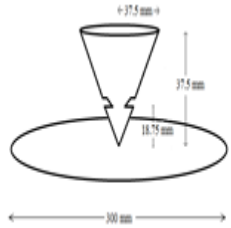

(b)

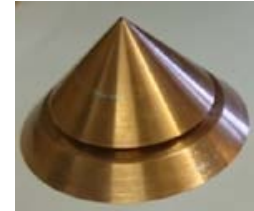

(c)
Fig. 3. The schematic diagram of (a) the simulated $15 \mathrm{~mm}$ deep slot at $26.25 \mathrm{~mm}$ (b) the simulated $7.5 \mathrm{~mm}$ deep slot at $18.75 \mathrm{~mm}$ and (c) the picture of the prototype slotted-cone antennas.

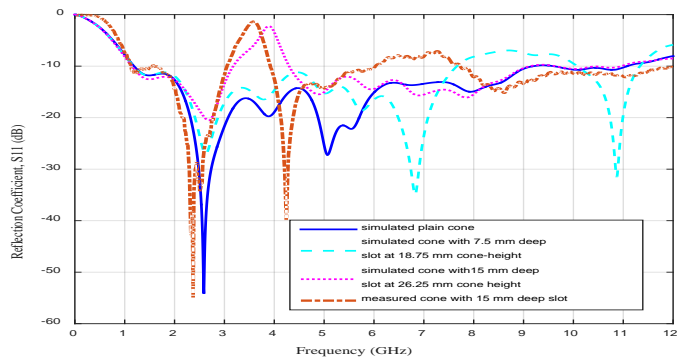

Fig. 4. Comparison of results for the simulated plain cone, single-slotted cones and the measured single-slotted cone with $15 \mathrm{~mm}$ deep slot

In order to investigate the effect of multiple slots on the operating frequency of the cone antenna, the two individual slot (7.5 mm and $15 \mathrm{~mm}$ deep) positioned at cone heights $h_{\mathrm{s} 1}=$ $18.75 \mathrm{~mm}$ and $h_{\mathrm{s} 2}=26.25 \mathrm{~mm}$ were placed on a single cone as shown Fig. 5(a) while maintaining the slot-width of $3 \mathrm{~mm}$ for the two slots. The sample prototype double slotted-cone antenna fabricated is shown in Fig. 5(b).

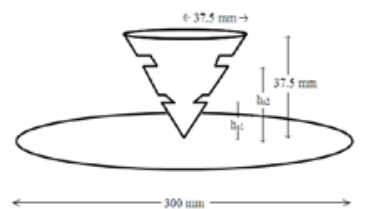

(a)

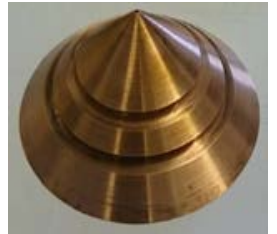

(b)
Fig. 5. (a) The schematic diagram of the simulated double-slotted cone antenna, (b) Prototype cone with 2 slots $-15 \mathrm{~mm}$ and $7.5 \mathrm{~mm}$ deep slots at $26.25 \mathrm{~mm}$ and $18.75 \mathrm{~mm}$ cone-height respectively.

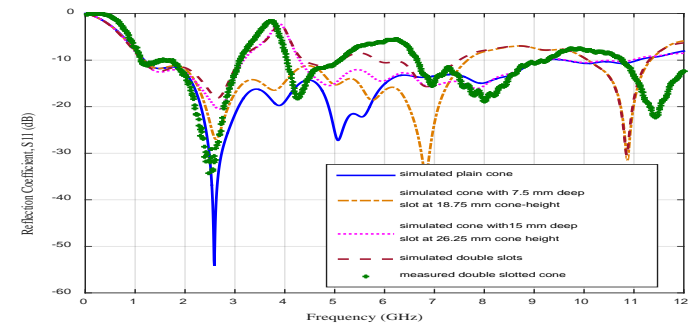

Fig. 6. Comparison of results for the plain cone, the $7.5 \mathrm{~mm}$ deep slot, 15 $\mathrm{mm}$ deep slot and the double slots

\section{RESUltS ANALYSIS AND DISCUSSIONS}

As shown in Fig. 4, the insertion of the $7.5 \mathrm{~mm}$ and $15 \mathrm{~mm}$ deep slots introduced anti-resonant frequencies at 7.67-10.06
$\mathrm{GHz}$ and 3.18-4.29 GHz frequency band respectively. Each of the slots produced a trap within the broad bandwidth of the cone, which resulted in two distinct bands instead of the single wide bandwidth produced by the plain cone. It was observed from the results that the trap frequencies produced by the slots are inversely proportional to the slot-depths. When the two slots were combined on a single cone to form a double-slotted antenna; two clear traps were produced creating three frequency bandwidths as shown in Fig. 6.The two traps are similar to the traps produced by individual slot.

\section{CONCLUSIONS}

Annular slots on solid cone produced trap frequencies in the wideband frequency creating multiple bandwidths depending on the number of slots applied. The slot application to solid cone antenna could be a useful tool to be annexed in frequency selection applications. The position and effectiveness of the trap depend on the depth of the slots.

\section{ACKNOWLEDGMENT}

This research was financially supported by the Schlumberger foundation.

\section{REFERENCES}

[1] W. Wiesbeck, G. Adamiuk, and C. Sturm, "Basic properties and design principles of UWB antennas,” Proc. IEEE, vol. 97, pp. 372385, 2009.

[2] J. G. Maloney and G. S. Smith, “Optimization of a conical antenna for pulse radiation: an efficient design using resistive loading,” IEEE Trans. Antennas Propag., vol. 41, no. 7, pp. 940-947, Jul. 1993.

[3] R. W. P. King and S. S. Sandler, "Compact conical antennas for wide-band coverage,” IEEE Trans. Antennas Propag., vol. 42, pp. 436-439, 1994.

[4] S. Palud, F. Colombel, M. Himdi, and C. Le Meins, "Compact multi-octave conical antenna,” Electronics Letters, vol. 44. p. 659, 2008.

Y. K. Yu and J. Li, “ANTENNAS,” Prog. Electromagn. Res. Lett., vol. 1, pp. 85-92, 2008.

[6] S. K. Oleksiy, "A Compact Biconical Antenna With Improved Radiation Pattern,” Union Radio Sci. Int. (URSI)-2008, pp. 2-5, 2008.

S. R. Best and S. Member, “A Multiband Conical Monopole Antenna Derived From a Modified Sierpinski Gasket,” vol. 2, pp. 205-207, 2003.

V. O. Doroshenko, O. E. Strelnytskyi, and O. O. Strelnytskyi, "Excitation of the Slot Conical Antenna (Theory and Experiment)," in X International Conference on Antenna Theory and Techniques, 2015, pp. 5-7.

[9] J. L. McDonald and D. S. Filipovic, "On the Bandwidth of Monocone Antennas,” IEEE Trans. Antennas Propag., vol. 56, no. 4, pp. 1196-1201, Apr. 2008. 